\title{
CONSIDERAÇÕES SOBRE O TRABALHO DE ANÁLISE INERENTE À LEITURA DE TEXTOS ACADÊMICOS
}

\author{
REMARKS ON THE WORK OF ANALYSIS INHERENT \\ TO THE READING OF ACADEMIC TEXTS
}

\author{
Adriana Santos Batista ${ }^{*}$ \\ Emanuelle Ventura de Freitas ${ }^{* *}$
}

\begin{abstract}
RESUMO: Este artigo parte de observações feitas por uma estudante de graduação, durante pesquisa de iniciação científica, acerca do "estranhamento" causado pela percepção de discursos de senso comum em dissertações e teses sobre educação e avaliações externas. Os questionamentos quanto à pertinência de alguns enunciados conduziram ao seu exame mais detido com vistas a verificar a existência ou não de tendências linguísticas e/ou discursivas nessas ocorrências. Assim, partindo dessa situação específica, assumimos como objetivo problematizar e apresentar possibilidades de leitura que contemplem um trabalho de análise de textos acadêmicos, por meio do qual eles possam ser considerados não somente como referências, mas como dados. Tomamos como fundamentação teórica os conceitos de heterogeneidade enunciativa e divulgação científica propostos pela autora Authier-Revuz $(1990,1998)$ e as distinções realizadas por Charaudeau (2013) sobre efeito de verdade e valor de verdade. Para as análises, foram selecionados trechos de três dissertações da área de Linguística e Literatura em que foram materializados diferentes discursos sobre educação. Como, em se tratando de textos acadêmicos, a sua escrita não necessariamente corresponde à produção de conhecimento, as discussões realizadas reforçam a importância de um trabalho de leitura que contemple a possibilidade de esses textos serem analisados ao serem lidos.
\end{abstract}

Palavras-chave: Divulgação científica; Senso comum; Escrita acadêmica.

ABSTRACT: This article is based on observations made by an undergraduate student during a scientific initiation research, about the "strangeness" caused by the perception of common sense discourses in dissertations and theses about education and external evaluations. The questions about the pertinence of some enunciations were conducted to a closer examination in order to verify the occurrence or not of linguistic and/or discursive trends in these occurrences. Thus, based on this specific situation, we assume that the goal is problematizing and presenting reading possibilities that contemplate an analysis of academic texts, through which they can be considered not only as references but also as dates. We took as theoretical foundation the concepts of enunciative heterogeneity and scientific disclosure proposed by Authier-Revuz (1990,

\footnotetext{
* Professora adjunta da Universidade Federal da Bahia (UFBA) e líder do Grupo de Estudos sobre Texto e Enunciação (GETEn).

** Graduanda em Letras da Universidade Federal da Bahia (UFBA) e integrante do Grupo de Estudos sobre Texto e Enunciação (GETEn).
} 
1998) and the distinctions made by Charaudeau (2013) about truth effect and truth value. For the analysis, we selected excerpts from three dissertations in the Linguistic and Literature area, in which different discourses on education were materialized. Considering, when dealing with academic texts, their writing doesn't necessarily correspond to the production of knowledge, the discussion developed reinforces the importance of a reading work that contemplates the possibility of these texts being analyzed when they're read.

Keywords: Scientific disclosure; Common sense; Academic Writing.

\section{INTRODUÇÃO}

Este artigo tem origem em duas pesquisas de iniciação científica (IC) realizadas entre 2019 e 2021 que tiveram como objetivo geral analisar tendências teóricas e discursivas em dissertações e teses da área de Linguística e Literatura sobre avaliações externas, defendidas entre os anos de 2015 e $2020^{1}$. Embora não se tratasse de objetivo inicial, as pesquisas acabaram por contemplar também um caminho analítico que procurou abordar uma inquietação suscitada pela leitura dos textos: a de que havia uma recorrência de passagens em que se materializava senso comum sobre educação ou sobre as avaliações externas, seja com o emprego de citações ou não.

O "estranhamento" de uma estudante de graduação em seus primeiros anos de formação acadêmica frente à escrita materializada em dissertações e teses constituiu-se como um indício da pertinência de textos acadêmicos serem tomados não somente como referencial teórico, mas também como corpus de análise para observação da constituição de sua escrita. Da mesma forma, a própria leitura que se realiza por pessoas que estão em etapas diferentes de suas caminhadas como pesquisadoras também pode se revelar como objeto de pesquisa, na medida em que permite compreender, por exemplo, a quais aspectos se dá mais ou menos ênfase.

No caso dos textos que compuseram o corpus das ICs, se inicialmente o foco estava na leitura de resumos e introduções para verificação de informações

\footnotetext{
1 "Caracterização da produção acadêmica sobre avaliações externas", de 2019 a 2020 com bolsa Pibic UFBA, e "Tendências teóricas e discursivas na produção acadêmica sobre avaliações externas", de 2021 a 2021 com bolsa Fapesb. Ambos foram orientados pela Prof. ${ }^{a}$ Dr. ${ }^{a}$ Adriana Santos Batista.
} 
objetivas (corpus, autores, conceitos mobilizados, tendências teóricas, etc.), em um segundo momento o movimento de leitura conduziu à percepção de que mesmo essas informações não eram tão facilmente perceptíveis. Assim, como objetivo colateral, surgido do próprio interesse em compreender como se caracterizam essas dissertações e teses como textos acadêmicos, buscamos analisar mais detidamente alguns enunciados com vistas a verificar possíveis marcas textuais que nos levassem a compreender a aparente dissonância com os textos.

O principal interesse, no que diz respeito à escrita desses trabalhos, reside na possibilidade de examinar como neles se materializam diferentes discursos sobre educação, não necessariamente comprovados ou provenientes da esfera acadêmica. Embora, em termos de heterogeneidade enunciativa, tratese de aspecto passível de ser examinado em produções com outras temáticas, levou-se em consideração o fato de o debate sobre educação e resultados de avaliações externas ser muito presente fora do âmbito acadêmico, e, portanto, permeado de discursos de senso comum.

Tal exame se relaciona diretamente a um dos objetivos do projeto Leitura e escrita no Brasil, Honduras, Angola e Chile: formação na universidade contemporânea e (re)produção de conhecimento², qual seja: "analisar o tipo de relação que o aluno de graduação e pós-graduação estabelece com a palavra alheia nas suas produções escritas". No caso das dissertações e teses sob análise, o relacionar-se com a palavra alheia diz respeito tanto à escolha das informações sobre avaliações externas que são consideradas como relevantes pelos pós-graduandos para compor os trabalhos, quanto às estratégias usadas para inseri-las. Para tanto, consideramos que ela pode se manifestar como heterogeneidade constitutiva ou mostrada.

Por ser ponto de partida para as análises, a relação da aluna de graduação com a palavra alheia tem papel central nas discussões aqui realizadas. Relação que se dá, principalmente, no nível da leitura e que se caracteriza pelo se permitir investigar o texto acadêmico, e não somente tomálo como fonte inquestionável.

\footnotetext{
2 Projeto coordenado pela Prof. ${ }^{\text {a }}$ Dr. ${ }^{\text {a }}$ Marinalva Vieira Barbosa, com financiamento aprovado no Edital Universal MCTIC/CNPQ № 28/2018, sob o processo número 427044/2018-9.
} 
De um total de 34 dissertações e teses localizadas no Catálogo de Teses e Dissertações da CAPES durante as pesquisas de IC (FREITAS, 2021), foram selecionados trechos de três dissertações para exemplificação. Tal escolha se deu por haver, nessas produções, passagens em que foram mobilizados enunciados que evidenciam senso comum sobre educação e avaliações. Com a explicitação desses números não se pretende afirmar que essa é a proporção de dissertações e teses em que a apropriação desses enunciados ocorreu; a seleção dos excertos para as discussões aqui estabelecidas buscou contemplar as características mais representativas do que se encontrou durante a leitura dos trabalhos.

\section{ASPECTOS TEÓRICOS}

Para pensar na presença de discursos de senso comum na escrita acadêmica, tomamos como ponto de partida o conceito denominado heterogeneidade enunciativa, cunhado pela autora Authier-Revuz (1990), bastante discutido e mobilizado no Brasil, principalmente, em trabalhos sobre discurso, enunciação e que tomam a escrita acadêmica como corpus de análise. Ao tomá-lo por princípio, consideramos que os discursos são atravessados por outros, que podem ou não ser evidenciados linguisticamente com diferentes tipos de recursos.

Segundo a autora, "somente o Adão mítico abordando com sua primeira fala em um mundo ainda não posto em questão, estaria em condições de ser ele próprio o produtor de um discurso isento do já dito na fala de outro" (AUTHIERREVUZ, 1990, p. 27). Em alusão à escrita de textos de diferentes gêneros acadêmicos, não é possível pensar sua existência desvinculada da produção anterior da área, seja ela citada ou não. Cada texto dialoga com os escritos anteriormente e com diferentes discursos, havendo ou não possibilidade de identificar explicitamente sua origem.

Tendo em vista que os enunciados carregam em si uma história, que pode se manifestar de modo aparente, a heterogeneidade constitutiva é estabelecida a partir da presença do outro no discurso. Assim, neste artigo quando se assume a presença de senso comum em textos acadêmicos, não se tem como base 
passagens em que há citações ou outras formas de inserção do discurso relatado, mas aquelas em que é perceptível a presença de discursos que circulam com frequência fora do âmbito acadêmico, prescindindo, portanto, de comprovação.

É possível fazer uma associação entre essa perspectiva de senso comum em textos acadêmicos e as distinções realizadas por Charaudeau (2013) entre efeito de verdade e valor de verdade. Para o autor, a forma como as pessoas entendem sua relação com o mundo toma por base crenças sobre o que é ou não é verdadeiro. Nessa concepção, as verdades e as crenças ligam-se a diferentes imaginários, a depender do grupo social; desse modo, grupos distintos estariam mais ou menos inclinados a considerar verdadeiras, ou cientificamente válidas, afirmações que são correntes no senso comum.

Para o autor, o valor de verdade não se dá de modo empírico, mas a partir de um conjunto de técnicas que permitiriam comentar o mundo; o efeito de verdade, por sua vez, diz respeito àquilo que se acredita ser verdadeiro, "Surge da subjetividade do sujeito em sua relação com o mundo, criando uma adesão ao que pode ser julgado verdadeiro pelo fato de que é compartilhável com outras pessoas e se inscreve nas normas de reconhecimento do mundo" (CHARAUDEAU, 2013, p. 49).

O valor de verdade depende, portanto, de objetividade e de uma série de métodos característicos do fazer científico. Como ele costuma ser atribuído a textos da esfera acadêmica, a presença neles de diferentes discursos, mesmo que provenientes de senso comum, contribui para Ihes conferir tal valor. Assim, ainda que a inserção de determinado enunciado em um texto acadêmico possa ter relação com as crenças de quem o escreveu, com aquilo que para ele possui efeito de verdade, o fato de se inserir em uma dissertação ou uma tese contribui para que esse enunciado passe a ter para seus leitores valor de verdade.

Aos olhos de uma estudante em estágio inicial de formação acadêmica, enunciados que the pareciam ora pautados no saber científico, ora no senso comum, muito se assemelhavam a textos de divulgação científica sobre educação e avaliação externas, com os quais já havia tomado contato, antes mesmo da graduação. Tal observação conduziu à busca por concepções sobre 
divulgação científica, dentre as quais destaca-se a estabelecida por AuthierRevuz em Palavras incertas: as não-coincidências do dizer:

Personificada, animada, a Ciência é "representada" no discurso da D.C.; este não fala o discurso da Ciência, mas somente o mostra: também longe de desestabilizar o funcionamento absoluto, o esclarecimento dos enunciadores não é mais do que um elemento da encenação; inscrito, na ordem do espetáculo, do "não verdadeiramente", o discurso científico que mostra a D.C. reforça, longe de colocar em questão, o "verdadeiro" discurso da Ciência como sua fonte e sua garantia na ordem do real." (AUTHIER-REVUZ, 1998, p.123 )

Para as reflexões aqui estabelecidas, tomamos o que a autora chama de encenação do fazer científico como representação desse fazer. Essa apropriação ampara-se na percepção de que, em textos como dissertações e teses, pode haver uma escrita próxima do discurso de divulgação científica, no qual a ciência é predominantemente mostrada. Nesse mostrar, que prescinde de evidência e comprovação, haveria espaço também para os discursos que encontram sua validade como efeito de verdade. Com isso pretendemos chamar a atenção para dois movimentos: 1) a presença de discursos de senso comum em dissertações e teses; 2) o fato de haver textos acadêmicos que se assemelham a textos de divulgação científica.

Nesse contexto, compreendemos como uma das tarefas da divulgação científica o que postula Authier-Revuz: "Transmissão de um discurso existente em função de um novo receptor, a D.C., dá-se, então, imediatamente, como uma prática de reformulação de um discurso-fonte (doravante D1) em um discurso segundo (doravante D2)" (AUTHIER-REVUZ, 1998, p. 108). A presença do senso comum se manifestaria então como uma possível reformulação de um discurso com valor de verdade, materializando-se somente como discurso segundo aparente, sem que sua origem seja atribuída. Esse procedimento estaria presente, por exemplo, em textos acadêmicos que partissem da premissa de que os estudantes brasileiros têm maus resultados nas avaliações sem, entretanto, apresentarem fontes para comprovação ou refutação. 


\section{ENTRE A CONCRETUDE E A ABSTRAÇÃO}

Há algo de muito frequente em discursos que circulam em diferentes contextos sobre os resultados das avaliações em larga escala, mencionar os maus resultados dos estudantes brasileiros é quase um caminho inequívoco a partir do qual se fala em educação. Em termos retóricos, o que chamamos de senso comum poderia ser considerado como lugar comum; a respeito de seu emprego, Fiorin faz a seguinte consideração: "O uso de lugares-comuns, em todos os sentidos que essa expressão ganha ao longo do tempo, e de lugares específicos também serve para apresentar uma tese como se fosse evidente por si mesma" (FIORIN, 2018, p. 202).

De fato, a recorrência dessa afirmação parece reforçar cada vez mais o seu efeito de verdade, como se não houvesse antítese ou refutação possível. Como enunciado recorrente e amplamente aceito, passível de ser empregado em diferentes circunstâncias, importam pouco as características do exame em questão ou as especificidades contextuais, pois a tendência é que cause pouco questionamento ou controvérsia enunciar que os estudantes brasileiros têm desempenho insuficiente em avaliações.

Essa aparente concretude, que pode ser entendida em termos de regularidade discursiva, guarda em si uma abstração quanto às especificidades desses resultados tidos como insatisfatórios, acerca disso seria possível questionar: a partir de qual perspectiva? Em quais avaliações? Tendo como base quais parâmetros? Quais resultados seriam adequados? Quais são as áreas avaliadas? A recorrência da afirmação geral acaba por deixar em segundo plano as especificidades, como se ela prescindisse de aprofundamento e explicações.

Passemos à análise de alguns excertos em que essas regularidades se manifestaram para observar o modo como tais enunciados se constituem.

\section{Excerto 1: Dissertação A (2019)}

As avaliações externas de Língua Portuguesa têm como foco avaliar o nível de leitura, verificando as estratégias e as habilidades desenvolvidas pelos estudantes. Os resultados dessas avaliações vêm preocupando o país e têm sido alvo de muitas discussões e estudos, uma vez que os alunos estão apresentando um desempenho frequentemente aquém do que se espera de um estudante na etapa avaliada. 
O excerto 1 se inicia com a referência a "avaliações externas de Língua Portuguesa" de forma ampla, sem especificações sobre quais seriam essas avaliações e suas respectivas características. Embora o início do enunciado contemple quaisquer avaliações externas de Língua Portuguesa, o foco "avaliar o nível de leitura" evidencia que não são consideradas aquelas que também se concentram nas habilidades de escrita. Apesar de, aparentemente, se tratar de uma afirmação pautada no conhecimento sobre os tipos de exames, observa-se uma generalização que pouco explica sobre sua natureza. Quanto aos resultados, esses são tomados mais em termos de seus efeitos do que de suas características, ressaltando-se o "desempenho frequentemente aquém do que se espera de um estudante na etapa avaliada", independentemente de quais sejam a etapa e o estudante.

A título de exemplo, se tomarmos uma tabela com resultados e metas do Ideb entre 2005 e 2009 dos anos iniciais do ensino fundamental, podemos observar que, com exceção da rede privada, nos anos de 2011, 2013, 2015, 2017 e 2019, todas as outras redes alcançaram as metas:

\section{Tabela 1: Ideb resultados e metas}

Anos Iniciais do Ensino Fundamental

\begin{tabular}{|c|c|c|c|c|c|c|c|c|c|c|c|c|c|c|c|c|}
\hline & \multicolumn{8}{|c|}{ IDEB Observado } & \multicolumn{8}{|c|}{ Metas } \\
\hline & 2005 & 2007 & 2009 & 2011 & 2013 & 2015 & 2017 & 2019 & 2007 & 2009 & 2011 & 2013 & 2015 & 2017 & 2019 & 2021 \\
\hline Total & 3.8 & 4.2 & 4.6 & 5.0 & 5.2 & 5.5 & 5.8 & 5.9 & 3.9 & 4.2 & 4.6 & 4.9 & 5.2 & 5.5 & 5.7 & 6.0 \\
\hline \multicolumn{17}{|c|}{ Dependência Administrativa } \\
\hline Estadual & 3.9 & 4.3 & 4.9 & 5.1 & 5.4 & 5.8 & 6.0 & 6.1 & 4.0 & 4.3 & 4.7 & 5.0 & 5.3 & 5.6 & 5.9 & 6.1 \\
\hline Municipal & 3.4 & 4.0 & 4.4 & 4.7 & 4.9 & 5.3 & 5.6 & 5.7 & 3.5 & 3.8 & 4.2 & 4.5 & 4.8 & 5.1 & 5.4 & 5.7 \\
\hline Privada & 5.9 & 6.0 & 6.4 & 6.5 & 6.7 & 6.8 & 7.1 & 7.1 & 6.0 & 6.3 & 6.6 & 6.8 & 7.0 & 7.2 & 7.4 & 7.5 \\
\hline Pública & 3.6 & 4.0 & 4.4 & 4.7 & 4.9 & 5.3 & 5.5 & 5.7 & 3.6 & 4.0 & 4.4 & 4.7 & 5.0 & 5.2 & 5.5 & 5.8 \\
\hline
\end{tabular}

Os resultados marcados em verde referem-se ao Ideb que atingiu a meta (fonte: site do INEP)

Ainda que seja possível falar em termos de recorrência de resultados insatisfatórios, tal acepção descarta o reconhecimento da possibilidade de superação de metas, como é o caso dos anos iniciais do ensino fundamental. A tabela é também ilustrativa de como as metas levam em consideração 
características de cada uma das redes; desse modo, embora o ldeb da rede privada de 2019 seja maior que o das redes estadual e municipal, a meta não foi atingida. Essa especificidade contradiz o discurso corrente segundo o qual a rede privada não só cumpre, como supera as metas estabelecidas.

A tendência a indicar o não atendimento a índices satisfatórios está presente também em outros enunciados, como:

\section{Excerto 2: Dissertação B (2016)}

Observamos que os resultados das avaliações externas de leitura, como os do Sistema de Avaliação do Estado do Rio de Janeiro - SAERJ (RIO DE JANEIRO, 2010) e da Prova Brasil (BRASIL, 2008), mostram que os alunos do Ensino Fundamental ainda não atingiram níveis satisfatórios de compreensão leitora. 1 1 Os resultados da Prova Brasil encontram-se disponíveis no site www.inep.gov.br." [informação em nota de rodapé]

No excerto 2, há a mobilização de enunciado semelhante ao do excerto 1, aludindo ao fato de os alunos do ensino fundamental não terem atingido níveis satisfatórios de compreensão leitora. Nesse caso, entretanto, há o recurso ao emprego da nota de rodapé logo após "compreensão leitora". Tendo em vista que a nota é inserida ao fim do período em que, além da Prova Brasil, fala-se também do Sistema de Avaliação da Educação do Estado do Rio de Janeiro (SAERJ), tem-se a expectativa de que se trataria de nota explicativa, que apresentaria mais informações sobre os índices de compreensão leitora atingidos. Contudo, trata-se de nota de referência em que se apresenta o endereço do site do INEP para uma possível consulta sobre esses resultados.

Se, por um lado, o emprego da nota de rodapé cria um efeito de atendimento às normas de escrita acadêmica, por outro, ele pouco acrescenta em termos do que é apresentado. A constatação, também perceptível no senso comum sobre educação, e aparentemente comprovada pela referência em nota de rodapé, conta com a expectativa de concordância do leitor para constar, sem explicações adicionais, em uma dissertação. Nesse ponto, não se pretende ressaltar a afirmação, que de fato pode ser confirmada com a leitura dos relatórios; a estratégia que se busca problematizar é o reduzido trabalho de escrita e comprovação quando se abordam temas aparentemente consensuais. 
Em um outro extremo, há também os enunciados que apontam para discursos não sobre os resultados insatisfatórios, mas sobre a insuficiência das avaliações. Para exemplificar, segue o terceiro excerto selecionado:

\section{Excerto 3: Dissertação C (2018)}

É importante destacar que essas avaliações são padronizadas, portanto não levam em consideração as especificidades de cada região brasileira e os investimentos que o poder público faz em cada escola. Essas avaliações foram se aperfeiçoando e acabaram se transformando em fins em si mesmos, isto é, avalia-se para satisfazer aos que financiam a educação e não visando a sua qualidade.

O sistema de ensino de especializou na agradável e leve tarefa de pensar essas avaliações, enquanto os professores se especializaram no duro afã de se produzir bons resultados, independentemente das condições de trabalho que são oferecidos aos mesmos.

Com relação ao primeiro parágrafo, destaca-se a referência "aos que financiam a educação", como se as avaliações fossem realizadas para satisfazêlos. Ora, se no âmbito público brasileiro, a educação é financiada com recursos públicos, os que financiam a educação poderiam ser compreendidos pela própria população; satisfazê-los corresponderia, portanto, a garantir a qualidade. No entanto, não é esse o significado decorrente do enunciado, tal aspecto se evidencia pela relação de contradição estabelecida no que se refere à preocupação com a qualidade.

Há a seguir uma polarização entre o sistema de ensino e os professores em termos do tipo de tarefa exercida. O emprego de "agradável e leve" em oposição a "duro afã", de forma irônica, evidencia papéis distintos atribuídos a cada um, dialogando com uma memória discursiva sobre as dificuldades da carreira docente. As caracterizações positivas com relação ao sistema de ensino ligam-se à satisfação mencionada anteriormente, como se o próprio sistema fosse a fonte de financiamento e avaliasse para se satisfazer. Mesmo se tratando de uma crítica às avaliações, ela tem pouca consistência na medida em que se caracteriza mais como uma defesa do trabalho dos professores apesar das determinações do que é nomeado como sistema de ensino. 


\section{CONSIDERAÇÕES FINAIS}

Posto que as análises aqui estabelecidas concentraram-se em enunciados de três dissertações, cuja escolha se deu por serem prototípicas, representativas de discursos de senso comum perceptíveis nas dissertações e teses lidas, não é possível falarmos em termos quantitativos em predominância desse modo de escrita nesses trabalhos. De todo modo, o estranhamento por sua presença nos textos nos dá indícios para refletirmos tanto sobre sua elaboração, quanto sobre sua recepção.

Em termos de elaboração, o fato de se tratar de temática amplamente abordada por diferentes esferas, não necessariamente acadêmicas, coloca à disposição uma série de discursos sobre os quais raramente há questionamento ou refutação, como é o caso do desempenho insatisfatório dos estudantes brasileiros. Inseridos, mesmo que sem comprovação, em textos acadêmicos, aos quais socialmente se confere valor de verdade, tais discursos são reafirmados e referendados. Nesse aspecto reside a aproximação desses textos com o que se dá na divulgação científica, não pelo caráter de transposição linguística, mas pela aparente simplificação de problemas complexos.

Deve-se considerar que, em se tratando de trabalhos de fim de curso, houve um trabalho anterior de leitura, avaliação e aprovação antes da divulgação pública dos textos. Assim, ao destacarmos os enunciados, não pretendemos evidenciar seus autores, mas chamar a atenção para modos de produção e circulação de textos acadêmicos em que tais construções são aceitáveis. Não se trata, portanto, de uma discussão sobre responsabilização, mas de compreender que, em textos acadêmicos, tem havido espaço para circulação de saberes que não necessariamente se constituem como produção de conhecimento. Cenário intensificado, entre outros fatores, pela tendência ao produtivismo, em que a produção de texto não necessariamente corresponde à produção de conhecimento.

Para o enfrentamento desse aspecto, além da atenção à própria escrita por parte de quem escreve, há que se pensar também no papel do leitor, na forma como ele lida com a palavra alheia. À medida que se tornam mais frequentes ocorrências de senso comum, mais se exige do leitor um olhar 
minucioso para o texto, um modo de leitura que pressupõe a análise, refutação e reconstrução daquilo que se lê. Com isso, reiteramos a importância de estratégias de leitura que, em diferentes níveis de formação, tomem os textos acadêmicos como materiais de análise, nos quais seja possível observar, compreender e questionar seus modos de constituição.

\section{REFERÊNCIAS}

AUTHIER-REVUZ, Jacqueline. Heterogeneidade(s) enunciativa(s). Tradução Celene M. Cruz e João Wanderley Geraldi. Cadernos de estudos linguísticos, Campinas, v. 19, p. 25-42, jul/dez.1990.

AUTHIER-REVUZ, Jacqueline. Palavras incertas: as não-coincidências do dizer. Campinas: Editora da UNICAMP, 1998.

CHARAUDEAU, Patrick. O que quer dizer informar: dos efeitos de poder sob a máscara do saber. In: CHARAUDEAU, Patrick. Discurso das mídias. São Paulo: Contexto, 2013. p. 31-63.

FIORIN, José Luiz. Argumentação. São Paulo: Contexto, 2018.

FREITAS, Emanuelle Ventura de. Caracterização da produção acadêmica sobre avaliações externas. 2021. 1 vídeo (4,49 min). Publicado pelo canal TV UFBA. Disponível em: <https://www.youtube.com/watch?v=UpkL-OrO_e4>. Acesso em 03 nov. 2021.

INSTITUTO NACIONAL DE ESTUDOS E PESQUISAS EDUCACIONAIS ANÍSIO TEIXEIRA. Disponível em <http://ideb.inep.gov.br/resultado/>. Acesso em 01 out. 2021. 